Article

\title{
Geo-Disaster Governance under the IAD Framework: The Case Study of Chongqing's Three Gorges Reservoir Region, China
}

\author{
Aobo Ran ${ }^{1}{ }^{1}$, Jingbo Fan ${ }^{2}$, Li Zhou ${ }^{3}$ and Chenggang Zhang ${ }^{1, *}$ \\ 1 Department of Sociology, Tsinghua University, Beijing 100084, China; rab15@mails.tsinghua.edu.cn \\ 2 School of Public Administration, University of International Business and Economics, Beijing 100029, China; \\ fanjb@uibe.edu.cn \\ 3 Chongqing Geo-disaster Prevention and Control Center, Chongqing 400015, China; \\ lizhou_cqgdpcc@outlook.com \\ * Correspondence: zcgice@tsinghua.edu.cn
}

Received: 30 May 2020; Accepted: 6 July 2020; Published: 8 July 2020

\begin{abstract}
Disaster governance draws attention from academics and policymakers, especially in developing countries. This paper shows how daily geo-disaster governance at local level operates in China and then reveals the causes of its pattern. To achieve the goals, we apply the Institutional Analysis and Development (IAD) Framework as the lens into the case of Chongqing's Three Gorges Reservoir Region. We find that China's daily geo-disaster governance, as a whole, is a top-down system where public sectors play an active role. It emphasizes technology, engineering, and profession, and features the matrix of fragmentation. The governance varies as the situations change and leaves disconnection among situations. The exogenous environment, several rules in action situations, and evaluative criteria shape the governance pattern altogether. Finally, we suggest that the government should change from disaster orientation to people orientation, from discontinuity to continuity, and from singularity to diversity.
\end{abstract}

Keywords: disaster governance; Institutional Analysis and Development Framework (IAD Framework); geological disaster; the Three Gorges Reservoir Region; China; Chongqing

\section{Introduction}

Disasters seriously undermine social well-being. Average annual financial loss by disaster has been 205.32 billion USD worldwide over the past 10 years since 2009, and the frequency of tremendous loss has shown an upward trend as well [1]. For developing countries, the impact of disasters could be especially brutal. Over 840 billion USD of economic losses were caused by disasters in poor countries from 1991 to 2010 [2], and China lost a total of 106 billion RMB (around 15.8 billion USD) to floods and geo-disasters in 2018 alone [3]. The figures show just how detrimental disasters are to the development of social well-being development. Facing the disaster-prone situation, China establishes a remarkable organization of disaster governance with rapid response [4], setting a great example which deserves in-depth research.

The social studies of disaster have emerged as an appealing topic, especially disaster governance. As risk is regarded as a social product constructed by institutions [5,6], disaster mingles institutional arrangement [7] with the political process [8]. Disaster studies should consider actors and their action patterns in the complete hazards cycle [9]. Furthermore, some scholars think future studies need an analyzing mechanism of power and society behind various patterns of governance [10]. Consequently, this paper studies how China's local level geo-disaster governance operates and what the possible determinants are. 
Fruitful academic achievements about Chinese disaster governance exist, but the research object and lens still can be improved. In terms of research object, in the Chinese context, most of them concentrate on one actor, such as government [11], NGO (Non-Governmental Organizations) [12], community [13], or civil society [14], and on a single situation, such as response [15,16] or reconstruction [13]. In terms of level, most studies focus on the national level $[11,12,17,18]$, with great catastrophes $[14,19,20]$, which the central government and even international organizations directly engage with, such as the Wenchuan Earthquake. The analysis at local level disaster governance in China could enrich the existing research. We answer how local-level geo-disaster governance works, and why it works in a certain pattern. In order to explore the causes of its pattern, we use the Institutional Analysis and Development (IAD) Framework [21] as the lens to conduct a case study.

Scholars think that disasters must be analyzed in a broader environment, such as an institutional regime [22]. Renn views disaster governance as a network containing actors, rules, routines, processes, and mechanisms [23] (pp. 8-11), and so do other researchers [5,6,8,24]. This indicates that disaster governance needs institutional analysis, including neo-institutionalism, the basis of the IAD framework. It concerns formal and informal mechanisms, structure among actors, and how to be an appropriate mechanism [9]. Besides institution, decision-making, and action, environment-related incentives and knowledge flow should be taken into consideration [25]. The IAD framework contains multiple actors, collective actions, different situations, and outside environment, which can appropriately analyze disaster governance.

Some scholars have found potential of the IAD framework in disaster issues and have initially connected them already. From 1967 to 2015, more than one hundred cases used the IAD framework to analyze governance of natural resources [26]. Since both natural resource (positive) and disaster (negative) are natural impacts [22], it is possible to apply the IAD framework into disaster studies. Ostrom views IAD framework as a multi-concept map being adept in analyzing hierarchical interaction $[21,27,28]$. Since disaster governance is a hierarchical social network [23], the IAD framework can clear its micro-structure and mechanism by dividing a phenomenon into a number of understandable parts to reduce its analytical complexity [29], and it is an explanatory framework answering our question of why action patterns form. Some studies have introduced institutional framework into disaster governance. Comfort firstly introduces the IAD framework into disaster governance and notes that it particularly suits problems under a given pressure, such as earthquakes [30]. This framework is used in US climate change governance [31], climate change adaption in the Philippines [32], and flood management [33]. These studies, though preliminary, have inspired us. In the following, we use the IAD framework to explore how and why actors act in certain ways at the local level geo-disaster governance.

The paper is structured into the following five parts: (1) lens, the content of the IAD framework; (2) study background; (3) disaster governance in the case of CQ's TGRR (Chongqing's Three Gorges Reservoir Region) under the IAD framework; (4) possible causes of the disaster governance according to the IAD framework; and (5) conclusion and policy suggestions.

\section{Lens: IAD Framework}

The IAD framework raised by Elinor Ostrom provides new institutionalism to governance and develops in ensuing years [21,34,35]. The framework consists of seven related variables (Figure 1): biophysical conditions, attributes of community, rules-in-use, action situations, interactions, outcomes, and evaluative criteria. In the initial framework, the rules combined with attribution of biophysics and community cause action situations and then generate the outcomes [36] (pp. 37-38). As it develops, the three exogenous variables all potentially influence structure and operation in action situations and their interactions influenced by evaluative criteria deliver outcomes [21] (pp.13 and 42). The outcomes in this case are the geo-disaster governance pattern. 


\section{Exogenous Variables}

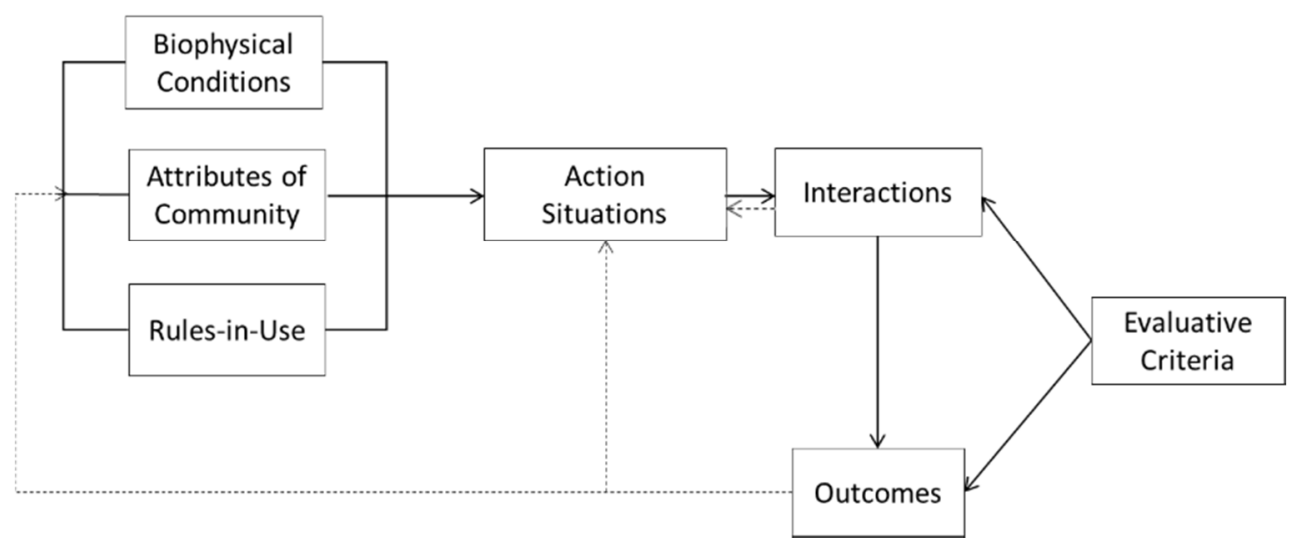

Figure 1. Institutional Analysis and Development (IAD) Framework. Source: [35].

Biophysical conditions, attributes of community, and rules-in-use are input sections, called external variables. Biophysical conditions are material resources and environment of action situations; attributes of community are the social and cultural factors, including trust, reciprocity, common understanding, social capital, and social repertoires; rules-in-use include formal rules, informal rules, and property rights; evaluative criteria include efficiency, fiscal equivalence, equity, accountability, adaptability, moral values, etc. [29]. We can use these concepts to illustrate factors that influence the action pattern in general.

Figuring out the determinations of action patterns needs zooming in on in action situations (Figure 2). Action situation is the place where actors are positioned, interact, and act around a specific theme linking to a potential outcome under several rules. The potential outcomes are the collective actions which are directly given by actors and positions and influenced by information about, control over, and net costs and benefits [21] (pp. 187-188). All the mentioned factors are impacted by the corresponding rules shown as arrows in Figure 2 [21] (pp. 189-190). All the rules collectively affect the structure and operation in one action situation [35].

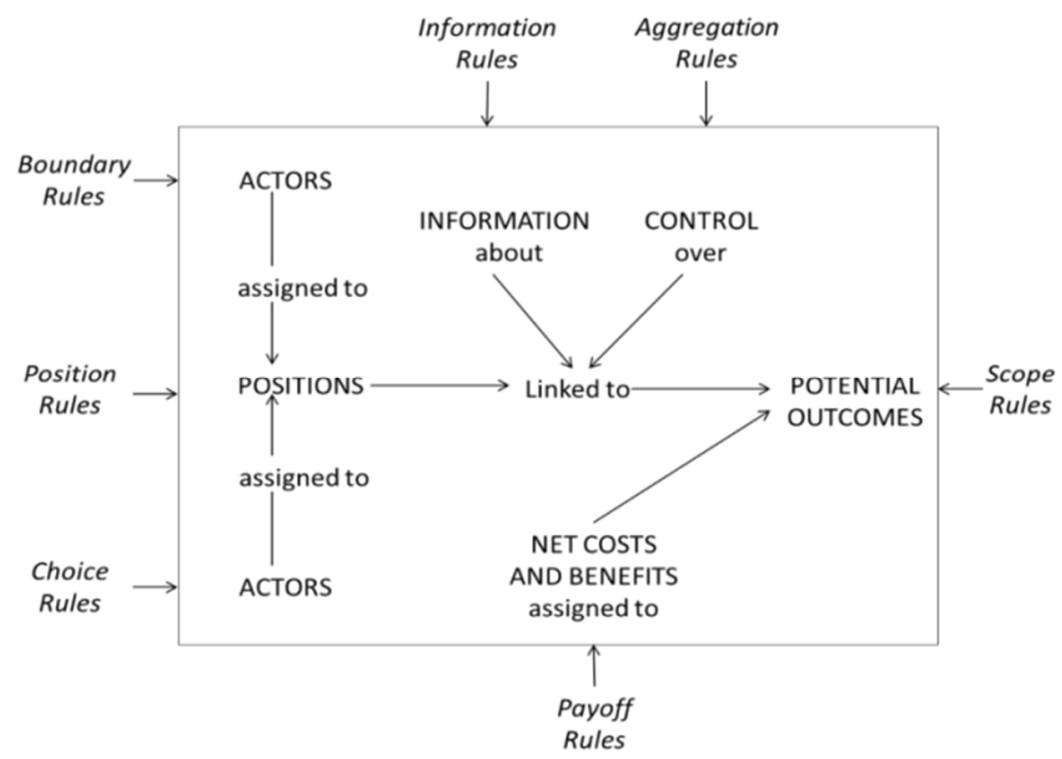

Figure 2. The structure of the action situation. Source: [35].

In this paper, "actors" refers to participants in disaster governance, such as CQ Bureau of Planning and Natural Resources (CQ BPNR), CQ Bureau of Emergency Management (CQ BEM). "Positions" refers to actors' identities, such as manager, organizer, and coordinator. Potential outcomes 
refer to collective actions of geo-diaster governance, such as mass monitoring and prevention (Qun Ce Qun Fang in Chinese). This means residents monitor and prevent disasters by ordinary people themselves with the assistance of the government and other organizations. "Information about" is the information about disasters that actors can gather. "Control over" refers to self-governance and negotiation among actors. "Net costs and benefits assigned to" refers to cost-benefit analysis of disaster governance. In terms of disaster governance, boundary rules affect how actors enter or leave disaster governance; position rules affect how actors are positioned in different disaster situations; scope rules affect the influential area of disaster governance; choice rules affect the approach actors choose to disaster governance; information rules affect the way actors gather information; aggregation rules affect the control level of disaster governance; payoff rules affect incentive and punishment in disaster governance. The rules do not definitely appear at the same time, and in some situations only some of them appear.

\section{Case and Methods}

\subsection{Case Background}

CQ's TGRR, one of the four most serious geo-disaster areas in China, is located in the upper reaches of Yangtze River, from $105^{\circ} 49^{\prime} \mathrm{E}$ to $110^{\circ} 12^{\prime} \mathrm{E}$ and from $28^{\circ} 28^{\prime} \mathrm{N}$ to $31^{\circ} 44^{\prime} \mathrm{N}$ (Figure 3). From 1982 to 2002, over 70 disasters happened in this area, including landslide, collapse, and debris flow. Due to climate change and increasingly intensive human activities, geo-disaster becomes gradually more serious. In 2003, there were 2480 spots of potential geo-disaster, and in 2015, this number increased to 3997.

The geo-disaster governance in CQ's TGRR is a multi-sectoral and multi-level structure involving many sectors and four levels, including municipality, county, town, and village. In a bigger picture of disaster government, each province takes territorial responsibility, and the Ministry of Natural Resources and the Ministry of Emergency take functional responsibility at the national level in brief. Every single level has its own according functional departments, which form a particular institutional background called the typical matrix of fragmentation (Tiao-Kuai Fen-Ge in Chinese).

In terms of preparedness, this area forms a great preparedness system. It includes professional monitoring, mass monitoring and preventing, engineering project, and emergency exercise, which the latter part elaborates on. The potential geo-disaster spots in this area are totally included in the geo-disaster governance system. In spite of the area being a disaster-prone zone, after twenty years' governance, no major spot of potential geo-disaster exists in this area. 


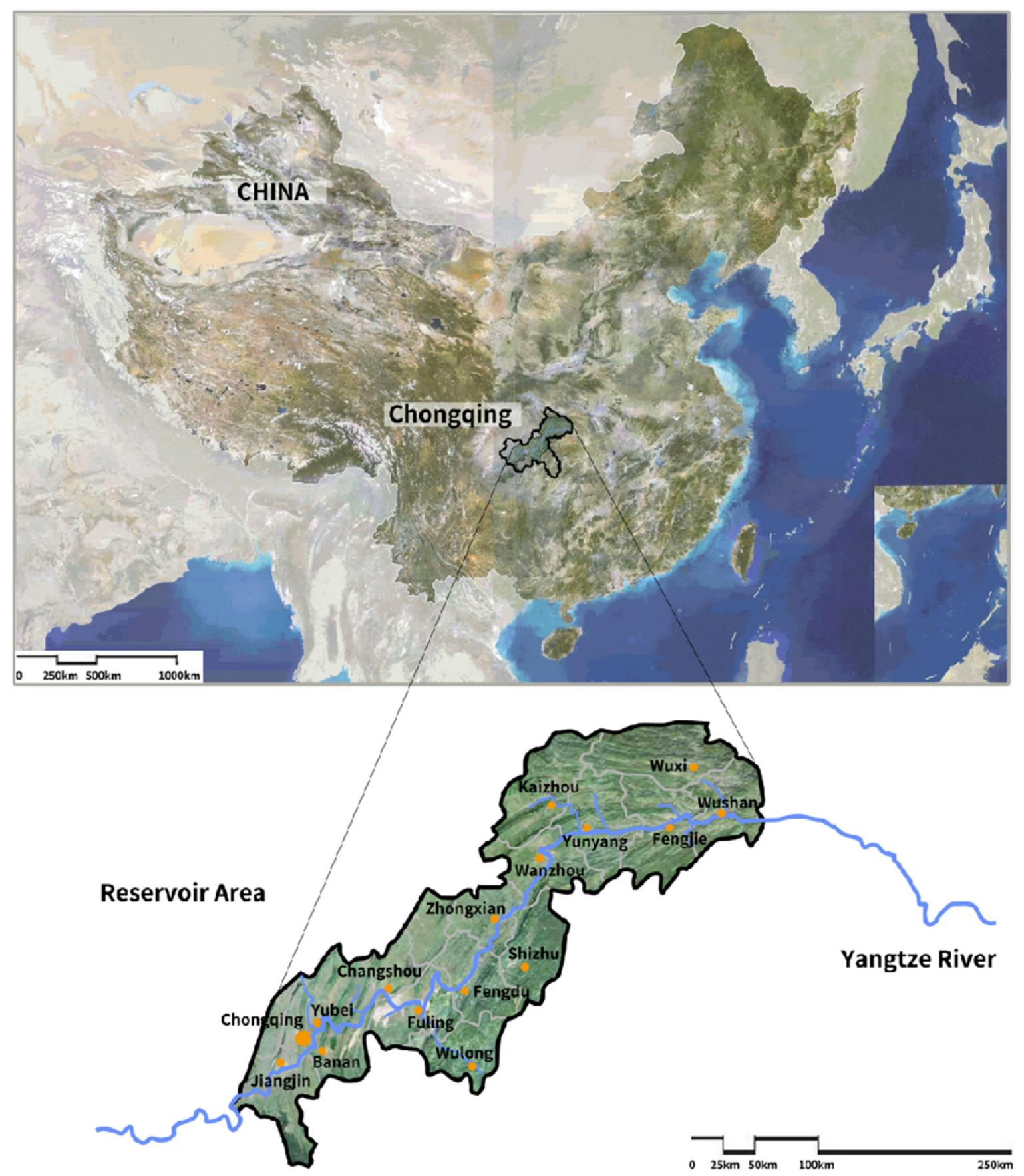

Figure 3. Chongqing's Three Gorges Reservoir Region.

\subsection{Reasons for Selection}

Because of typicality, importance, and feasibility, we select CQ's TGRR as the case. It is typical because geo-disasters always occur in this area as we claimed before. Meanwhile, the disaster governance of this area is advanced and is viewed as the model in China. Research on this area can benefit both theory and policy. The Three Gorges Dam, the biggest dam in the world, aggravated geo-disaster in this area, which has long been a controversial issue in academia and mass media alike. The leadership stresses the importance of geo-disaster governance in this area and its value to China [37]. In terms of feasibility, we have a great relationship with organizations for disaster governance in CQ's TGRR, such as CQ BPNR and governments in different levels, so we can access governors, staff, and materials. 
The following part applies the IAD framework in geo-disaster governance, including exogenous variables and collective actions in three situations.

\section{Exogenous Variables}

\subsection{Biophysical Conditions}

The geological conditions render CQ's TGRR as one of the most environmentally vulnerable areas in China. This area lies on the boundary between China's second and third geological ladders, and the Yangtze River strongly downcuts and erodes the bank. Hence, it is the area of terrain fragmentation that hugely varies in elevation, and $61.47 \%$ of the bank areas belong to sloping fields whose gradient is over 15 degrees [38].

Weather conditions aggravate environmental vulnerability. According to the reports on geo-disasters in this area from 2008, geo-disasters are closely related to heavy rain. CQ's TGRR possesses high annual precipitation, especially in the eastern regions where annual precipitation ranges from $800 \mathrm{~mm}$ to $1400 \mathrm{~mm}$ [39]. Rainfall concentrates on the flood season from 1 May to 30 September, and the frequency of rainstorm (Daily rainfall $\geq 50 \mathrm{~mm}$ ) is two to five times a year [39]. For instance, an extraordinary rainstorm on 31st August 2014 caused a series of geo-disasters [40]. Furthermore, the rainstorm becomes increasingly uncertain due to climate change [41], so the geo-disaster governance becomes gradually challengable.

Biophysical conditions are shaped by not only by nature but also by human activities. The population in this highly eco-sensitive and disaster-prone zone has grown from 18.5898 million in 2005 to 20.8668 million by the end of 2014. [42]. The increasingly large population results in constant and colossal human activities. In particular, constructions, such as the Three Gorges Project, reshape biophysical conditions, jeopardizing geological stability and deteriorating biophysical conditions in this area [43].

Biophysical conditions in CQ's TGRR determine that people cannot eliminate geo-disasters and have no choice but to co-exist with them. While the existing spots are governed, new risky spots still appear, caused by road construction, rural housing construction, and informal urban expansion. Reservoir filling, reservoir drainage, and rainfall possibly make these potential risks into real disasters eventually.

\subsection{Attributes of Community}

Reciprocity and awareness are positive in this area. Reciprocity in the area is strong because of the collective memory of the Three Gorges. After the Three Gorges Project, TGRR has become a sensitive region in terms of not only ecology but politics as well, since it caused huge numbers of reservoir immigrants: 1.0391 million people, 12 cities, and 106 towns resettled in CQ's TGRR [44]. It forms the spirit of immigration, including dedication, cooperation, and struggle [45], and makes up forthrightness, frankness, and enthusiasm of CQ's people [46]. Because of the limited land, high density of population, and the economy, and the frequency of geo-disaster from disasters would be enormous, arousing much attention to disasters in the community. Additionally, scientific communication about disasters has strengthened public awareness of disasters in this area.

However, residents in this area lack formal knowledge about disaster in general. They possibly have everyday experience and lay knowledge of disaster, but they are more about living with disasters together rather than emergency response. Most residents do not get enough education and lack scientific understanding of disaster governance, especially in rural areas, where disasters happen more frequently. According to an interview with a staff member [47], in 2006, a man who found the geo-disaster did not take refuge in time but stepped forward to watch the surge, which made him die. Moreover, the malfunction is possibly attributed to the new environment caused by the Three Gorges Project that residents cannot understand through existing knowledge. As an interviewee 
said, "information about geo-disaster spreads quickly among residents, but sometimes information containing rumors is distorted and actions are not appropriate either".

\subsection{Rules-in-Use}

Rules-in-use include formal rules and informal rules. Formal rules include official documents, work compilations, work manuals, work plans, and other written documents. Formal rules include two levels, the national level, such as Regulation on the Prevention and Control of Geologic Disasters (24 November 2003), and the municipal level, such as Measures of Chongqing Municipality Prevention, Control and Management of Geological Disaster (30 September 2007), and Chongqing Municipality Implementation Plan for Strengthening Risk Management of Emergency of Land and Housing Industry (August 2015). More precise rules that affect action patterns would be analyzed in Section 5.2.

Informal rules come from public sectors and the society. The former mainly refers to leaders' instruction. Although instructions are not mandatory, they would be conveyed level by level relying on formal organizations. They are sometimes even more efficacious than formal rules [48]. The latter generally refers to spontaneous actions by residents. Public sectors still participate in bottom-up activities, so informal rules are comparatively weak in this case.

\section{Collective Actions in Three Situations}

This section analyzes geo-disaster governance under three situations including pre-disaster, in-disaster, and post-disaster. We introduce all actors first and then discuss in detail their positions and collective actions. Actors are mainly categorized as public sector, society, expert, and business. Actors in different situations can be seen in Table 1. The narration of each situation corresponds to the logic shown as an arrow from positions to potential outcome (Figure 2), so we identify actors and their positions and then describe collective actions.

Table 1. Actors in Geo-disaster Governance.

\begin{tabular}{|c|c|c|c|c|}
\hline Situations & Public Sector & Society & Expert & Business \\
\hline Pre-disaster & $\begin{array}{l}\text { CQ BPNR, County government, Town government, } \\
\text { Village committee, County BPNR (including } \\
\text { Monitoring Station of Geology and Environment) }{ }^{1}\end{array}$ & $\begin{array}{l}\text { Resident as } \\
\text { monitor and } \\
\text { worker }\end{array}$ & Expert & $\begin{array}{l}\text { Enterprise, } \\
\text { Geological } \\
\text { Team }^{2}\end{array}$ \\
\hline In-disaster & $\begin{array}{c}\text { CQ Municipal government, CQ BPNR, CQ BEM, } \\
\text { CQ Construction Commission, CQ Transport } \\
\text { Bureau, CQ Water Resources Bureau, CQ } \\
\text { Supervisory Commission, CQ Public Security } \\
\text { Bureau, CQ Civil Affairs Bureau, CQ Finance } \\
\text { Bureau, CQ Health Commission, CQ City } \\
\text { Administration Bureau, CQ Meteorological } \\
\text { Administration, CQ Office of Chengdu Railway } \\
\text { Bureau }\end{array}$ & Victim & Expert & \\
\hline Post-disaster & $\begin{array}{l}\text { Relevant CQ municipal subordinated departments, } \\
\text { County government, Subordinated departments of } \\
\text { county government, Town government }\end{array}$ & $\begin{array}{l}\text { Victim } \\
\text { including } \\
\text { worker }\end{array}$ & Expert & $\begin{array}{c}\text { Enterprise, } \\
\text { Geological } \\
\text { Team, Bank, } \\
\text { Insurance }\end{array}$ \\
\hline
\end{tabular}

Notes: ${ }^{1}$ Actors in in-disaster situation is in case of municipal level. If it is in county level, all the CQ would be replaced by County. ${ }^{2}$ Geological team, as state-owned enterprise, is a distinctive actor which started in the Minguo period. Its main function changed from geological survey and scientific research to prospecting after 1949 and increased to engineering after the 1980s. Nowadays, almost geological teams transit into company but still keep the name.

\subsection{Pre-Disaster Governance}

\subsubsection{The Positions in Pre-Disaster Governance}

Pre-disaster governance refers to the collective actions to reduce potential losses caused by disasters before they occur. CQ BPNR is the governor guiding all actions in the situation of pre-disaster 
governance since it designs all frameworks and controls the financial resources. The concrete actions of the governor depend on the internal department, the Department of Geological Exploration, and the subordinates organizations, the Geo-disaster Prevention and Control Center and the Municipal Monitoring Station of Geology and Environment. County government plays the role of the coordinator. Executors include County BPNR, town government, village committee, geological team, enterprise, and residents. Although all of them are executors, they are still structured as a hierarchical system in which County BPNR tops. Experts system provides professional advice to ensure the technological reliability of the system.

Pre-disaster governance is integrated by four collective actions, professional monitoring, mass monitoring and preventing, engineering project, emergency exercise. The former two pave the foundation for the whole governance because they provide basic information to support decision-making. Governors can decide whether engineering projects are needed according to these data. The former three aim to reduce disasters' risks, while the last one aims to increase residents' resilience. Additionally, the last one is decided by BPNR in municipal or county level as well. Therefore, the governance, as the bigger picture, is a top-down system, although the mass monitoring and preventing, as a small piece, is a bottom-up system.

\subsubsection{The Collective Actions in Pre-Disaster Governance}

\section{Professional Monitoring}

Professional monitoring aims to monitor potential disaster spots by the monitor system equipped with advanced technology, which is established by the public sector.

CQ BPNR undertakes design, planning, coordination, and financial supports of the system, including designing and managing the whole framework, organizing inspection and acceptance of projects, guiding the professional monitoring in each district and county, gathering and analyzing the information of monitoring and warning, organizing investigation, and technical negotiation. County government coordinates CQ BPNR and other public sectors at the county level. County government can mobilize resources in its territory to support related actions.

County BPNR is supervised by CQ BPNR functionally and county government territorially at the same time. County BPNR takes charge of construction and operation of professional monitoring projects, supervising and controlling project schedule, compiling planning and programs, submitting annual implementation plan of professional monitoring to CQ BPNR and county government, organizing the final acceptance of professional monitoring projects, annual technical consultation on professional monitoring in county level, and supervising the practical work of professional monitoring. The Monitoring Station of Geology and Environment in the county level takes responsibility for forefront works including conducting professional monitoring, summarizing and analyzing data, writing monitoring reports, and compiling annual implementation of professional monitoring. Town government assists County BPNR by protecting facilities, providing human resource, and checking on the attendance of staff.

The expert system cooperates with BPNR, mainly on the municipal level, regarding technical consultation. Its activities include providing suggestions for the professional monitoring system and participating in annual acceptance and evaluation of professional monitoring.

This collective action is a top-down system needing technical expertise. CQ BPNR decides the whole framework of professional monitoring with the help of the expert system. County BPNR just implements what the supervisor decides with the coordination of the county government. Ordinary people are excluded from this action. The professional monitoring combines with advanced technologies requiring specialized knowledge, such as geological data to evaluate risk, GIS (geographic information system) to gather space information, and ICT (information and communications technology) to transfer data. 
Mass Monitoring and Preventing

Mass monitoring and preventing refer to how residents monitor and prevent geo-disaster by themselves with assistance from public sectors. They derive from the instruction of Zhou Enlai, the first Premier of the PRC. He proposed that earthquake prediction needs "mass monitoring and preventing, combining mass and experts, combining the indigenous and the foreign" [49]. Though not efficient for earthquakes, it benefits other types of geo-disaster, such as landslide and debris flow, which this paper focuses on.

CQ BPNR designs the framework as formal rules that regulate all actors. Specifically, it supports the whole system by purchasing equipment and organizing technical training and gathers all data from the subordinates.

Different from professional monitoring, which relies on technology, mass monitoring, and prevention centers on monitors. Monitors are volunteer residents whose allowance is symbolic and comparatively low, which ranges from 800 to $1000 \mathrm{RMB}$ per year. They take responsibility to patrol and inspect the spots of potential disaster, measure and record the required data at a regular time, and then report these data to town government by monitoring equipment. If they find an urgent dangerous situation, they can issue the early warning signal and evacuate people in this area. County BPNR writes plans about mass monitoring and preventing, handles the routine and data, organizes technical training, guides projects operation, and holds demonstration projects. Town government shoulders responsibility for these parts: selecting monitors from volunteers, organizing skills training and legal advocacy relating to geo-disaster, gathering data from monitors and reporting them to County BPNR, checking work attendance of monitors, and being on duty for $24 \mathrm{~h}$ in flood season, storage period, and discharge period. The village committee supervises and urges monitors to record data and ensures monitor equipment.

Expert system ties with monitors through BPNR in municipal and county level who organizes the session to train staffs in knowledge about geo-disasters. In this system, knowledge diffusion is based on hierarchy. People in upper level (e.g., staffs in CQ BPNR) who have been trained would instruct people in the lower level (staffs in County BPNR) to guarantee that they have basic skills.

This collective action is a bottom-up system relying on monitors selected from residents in disaster-prone areas. The system combines concrete everyday experience and technical training in order to help monitors to live with and to deal with disasters easily. CQ BPNR designs the framework for the others; County BPNR and town government ensure the implementation of this framework. Skill training and high-tech equipment play an important role because the public sector believes these can smooth the whole framework and authorize the information. Monitors can even obtain iPads and personal computers in some cases.

\section{Engineering Project}

Engineering projects are the main way to directly reduce risks in CQ's TGRR. This collective action utilizes engineering as the tool to transform geological conditions from unstable status to stable status. Engineering projects cannot cover all potential spots but some major spots.

CQ BPNR takes responsibility for approving projects from county government, designing administrative process of projects, supervising processes of key projects, and organizing project acceptance. For some key projects, CQ BPNR would be the factual Party A in the name of Geo-disaster Prevention and Control Center and would provide all funding for the projects.

County BPNR, as Party A, confirms which spot of potential geo-disaster deserves engineering governance. Enterprise and geological team bid project provided by County BPNR. Residents can be enrolled as workers of projects. In most cases, due to qualification, geological team would undertake most projects, and enterprise can only be the subcontractor and supplier. County BPNR registers the running condition of the project that the enterprise or geological team completes for reference in one or two years after the completion. During this period, Party B must take responsibility for its safety. 
The expert system participates in project approval and acceptance charged by BPNR in municipal or county level and provides professional advice. BPNR in both levels and geological teams, in some circumstances, would temporarily hire experts for technical guidance.

The whole collective action is a top-down system occupying the main share of the related financial allocation. CQ BPNR has decisive power and controls money resources. County BPNR has comparative strong power as well because it is the only executor of management issues including finance and bidding. Only with the permission from the institutions can the other actors enter into the system.

\section{Emergency Exercise}

The framework of emergency exercise is the same as the emergency responses the next section describes. The only difference is that emergency exercise deals with assumptive disaster rather than the real disaster the emergency response deals with. Its place and time are decided by BPNR in municipal or county level depending on its scale.

\subsection{In-Disaster Governance}

\subsubsection{The Positions in in-Disaster Governance}

In-disaster governance aims to respond to geo-disaster immediately. CQ BPNR is the governor in emergency duty, and the Headquarters is the governor in emergency response, which indicates that there is a gap within a single situation. When the emergency duty transfers into emergency response, the governor changes simultaneously. The actions in the first situation except mass monitoring and prevention are conducted inside BPNR, which forms a top-down vertical system. Although the Headquarters is the leader, the structure of the second action is a comparatively horizontal system consisting of organizations at the same level. The executors in the first one are the subordinate organizations inside BPNR, while the executors in the second one are the functional departments belonging to local government. Experts, CQ Meteorological Administration, and some engineers from functional department are experts system. Residents or victims are of no significance in this situation, since they are passively governed by executors and do not actively participate.

\subsubsection{The Collective Actions in in-Disaster Governance}

\section{Emergency Duty}

Emergency duty is a watch system for gathering and reporting information to response contingencies of geo-disaster. If there is no disaster, it is continuous and everyday work, while it changes to the forefront of emergency work when disaster happens.

Emergency duty is a collective action ensuring communication. CQ BPNR gathers information from the subordinate organizations and reports information to the Ministry of Natural Resources and Chongqing Municipal Government. County BPNR gathers information from land-related organizations in the town level and reports information to county government and CQ BPNR. At least one person should be on duty for $24 \mathrm{~h}$ in the office of BPNR at each level during the flood season. On the other days, they should be on duty by telephone connection, but their location is not limited.

The information originates from professional monitoring and mass monitoring and prevention, including the first information, the continued information, and the final information. The first information includes the time of the incident and receiving this information, the type, the scale and losses of disaster, and the preliminary measures. The continuing information includes the situations of emergency response, measures, disposal, and investigation. The final information is the comprehensive report of emergency response. When County BPNR receives the first information, it verifies and judges the clue. If it is or would become a large-level or even a particularly large-level geo-disaster, County BPNR should direct report to CQ BPNR, which will report to Ministry of Natural Resources. Facing a large level or even a particularly large level geo-disaster, the latest news should be followed, 
updated, and reported to the superior immediately by BPNR in both levels, and the final report should be submitted in time. In medium- and small-level geo-disasters, only the County BPNR would take these actions. All information about disaster should be reported to the Ministry within $4 \mathrm{~h}$ after a disaster happens. The superior should receive the telephonic report in $30 \mathrm{~min}$ and the written report in $1 \mathrm{~h}$ after receiving the first information from the subordinate.

Emergency duty functions as the information transmission through the hierarchical functional department. The involved levels depend on the scale of geo-disaster; the larger scale the geo-disaster is, and the higher level of BPNR is involved. The information is transmitted from the lower to the higher, mainly as a functional department's inner activity. Efficiency of emergency duty relies on the strict requirements of procedure, contents, and timeliness.

\section{Emergency Response}

Emergency response in this CQ's TGRR includes municipal level and county level. The frameworks of two levels are almost the same, and the only difference is the level of functional departments. In county emergency response, most of the involved organizations are at county level (e.g., County BPNR, County Government); in the municipal one, most of them are municipal level (e.g., CQ BPNR, CQ Municipal Government). The following only provides in-disaster governance at municipal level, since the county-level one can be deduced.

This collective action includes coordination, investigation, rescue, medical care, public security, traffic control, and temporary rehabilitation. CQ Municipal Government leads the Emergency Headquarters to gather and circulate information, design schedule of emergency disposal, and plan resources as a whole. All the collective actions would be administrated by the Headquarters.

In this situation, functional departments shoulder the related actions.

- Coordination is conveying the information to subordinates, summarizing information to superiors, and allocating resources horizontally, which CQ BEM leads and CQ BPNR, CQ Public Security Bureau, and the county government participate in.

- Investigation is figuring out and reporting causes of disasters to the Headquarters and verifying property losses and casualties, which CQ BPNR leads and CQ Supervision Committee, CQ Civil Affairs Bureau, and CQ BEM participate in.

- Rescue, the core of this situation, transfers victims to a safe area and is conducted by the Headquarters and is executed by the local government.

- Medical care conducted by CQ Health Commission aims to provide on-scene care, transfers the wounded to the nearby hospital, and allocates resources of health.

- Public security is setting a precautionary area for geo-disaster conducted by CQ Public Security Bureau.

- Traffic control, conducted by CQ Public Security Bureau and participated in by CQ Transport Bureau, aims to manage traffic in certain areas.

- Temporary rehabilitation is conducted by the Headquarters and executed by the local government aiming to settle residents in a certain area.

- The expert system provides useful information for the Headquarters who would make some decisions based on the information. For example, CQ Meteorological Administration provides the weather condition to support decision-making. The Headquarters hires some experts to consult professional advice in some cases.

\subsection{Post-Disaster Governance}

\subsubsection{The Positions in Post-Disaster Governance}

Post-disaster governance aims for a prompt recovery from disasters. Being different from the previous two situations, post-disaster governance is a territorial management by each disaster-affected 
county, so the governor is the county government rather than the functional department. Its subordinate departments and enterprises are the main executor; meanwhile, banks, insurance companies, victims, and experts participate as well. The governance appears as technological choices decided by the governor, conducted by the inferior organizations, and implemented as business contracts involving other actors, such as company, bank, insurance, and residents.

\subsubsection{The Collective Actions in Post-Disaster Governance}

County government takes a series of actions including site selection, construction and maintenance, which seem like constructing a new habitat involving almost all departments of the county.

Site selection, as the basis of post-disaster governance, includes a comprehensive assessment of the disaster condition, selecting original place or another place to reconstruct according to the assessment, and planning a new habitat. These issues are decided by the county government and executed by subordinate departments, especially County BPNR.

Reconstruction, the principal part of post-disaster governance, includes civil construction, infrastructure construction, and construction for public welfare and production facility. Civil construction ensures land expropriation, land leveling, and victims' housing. Infrastructure construction includes reconstruction public utilities including transportation, water, power, gas, communication, and cable television. Construction for public welfare and production facility includes reconstruction and maintenance of schools, hospitals, factories, markets, etc. Within this process, the County Development and Reform Commission and the County Construction Commission are powerful.

Maintenance refers to relevant services during the construction, such as public security, pacifying the victims, and distributing materials, which are mainly implemented by town government and County Public Security Bureau and County Civil Affairs Bureau.

Residents participate in the actions through employment, which means some of them change from passive actors to active actors. Meanwhile, the county government needs welfare-to-work to reduce social risks. Enterprise, bank, and insurance companies are indispensable as well, which participate in the construction through contracting projects, lending, and indemnity respectively. Experts and technicians from public sectors provide technical suggestions throughout post-disaster governance, which plays an important role since it resembles a large engineering project.

\subsection{The Governance in Changing Situations}

In sum, we provide a simplified diagram to show how actions connect with each other (Figure 4). In pre-disaster situation, CQ BPNR commands executors in terms of professional monitoring, engineering project, emergency exercise, and assists mass monitoring and prevention; executors provide feedback to CQ BPNR from equipment in professional monitoring and from local people in mass monitoring and preventing, and mobilize local people in the other two actions. In in-disaster situation, CQ BPNR directs BPNR at county-level, providing information for it as emergency duty; the Headquarters led by territorial government leads subordinate functional departments, which mobilize and organize local people. In a post-disaster situation, local government assigns work to corresponding subordinate departments; departments fulfill their own duty and publish tenders to invite businesses that hires local people, which benefit local people eventually. 


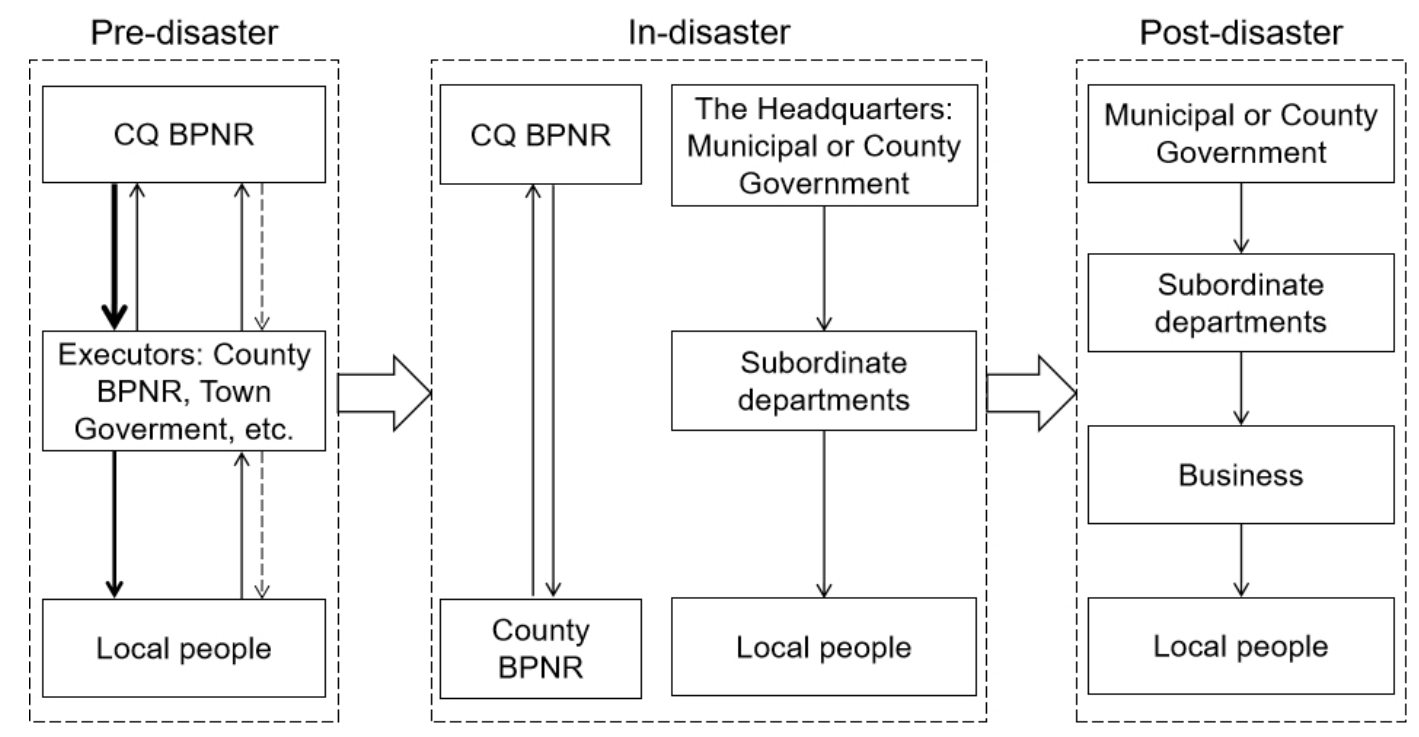

Figure 4. The overview of collective actions.

\section{Interactions among the Factors}

In order to reveal possible causes of geo-disaster governance, this section discusses interactions among the factors under the IAD framework. Specifically, we reveal how exogenous variables and rules in action situations influence the collective actions of disaster governance.

\subsection{Exogenous Variables}

\subsubsection{Biophysical Conditions}

Biophysical conditions considerably construct collective actions, specifically mass monitoring and prevention, and in-disaster governance. Spots of potential geo-disaster are distributed so widely in CQ's TGRR due to its biophysical conditions that professional monitoring can not cover all of them. After 2008, new spots of potential geo-disaster have appeared every year except 2012 and 2013, which means accidental and unexpected geo-disasters decrease the efficiency of GIS and automatic equipment. Mass monitoring and prevention, whose requirements are low, costs a little and covers broadly. If professional monitoring covered widespread geo-disasters in this area, it would cost a huge amount of money and resources, which the local government cannot support. Therefore, mass monitoring and prevention with the characteristic of bottom-up, which needs less money, suits the context.

Biophysical conditions render CQ BPNR constantly important. The causes of geo-disaster, including reservoir filling, reservoir drainage, and rainfall, which have a cross-county effect, shape in-disaster governance. Since 2008, disaster and risk situations caused by reservoir filling account for $31 \%$ of the total, the situations caused by reservoir drainage account for $20 \%$ of the total, and the situations caused by rainfall account for $48 \%$ of the total [50]. Reservoir drainage and filling affect areas along the Yangtze River simultaneously and raining, which would cause disaster in this area is always regional rather than small-scale, which indicates the possible spots of geo-disaster rarely happen in a small area but appear in a big region surpassing what a county government can handle. Therefore, CQ BPNR bears weighty responsibility in the former two situations.

\subsubsection{Attributes of Community}

Attributes of community mainly influence mass monitoring and prevention. Because of the strong reciprocity and the great sense of identity, the social network is comparatively robust and residents have enthusiasm to engage in bottom-up activity, which is the basis of mass monitoring and prevention. 
Yet ordinary people lack formal knowledge of geo-disasters, so the hierarchical structure of training from experts is necessary in order to fill the gap of scientific alternatives to risks.

\subsubsection{Rules-in-Use}

The structure of rules-in-use influences the structure of geo-disaster governance since all the collective actions are governmental behavior instead of civil behaviors. Informal collective actions rarely exist in the daily governance because rules-in-use, whose majority is formal rules, authorizes the main actors and their positions in three situations. More details about how rules affect collective actions are given in the next section.

\subsection{The Rules in Action Situation}

\subsubsection{Boundary Rules}

Boundary rules influence how actors enter or exit the action situation. Almost activities about geo-disaster governance are constructed or even regulated by formal rules, so governance in three situations is top-down system and the governor has great power. Since the formal rules are rigid, the appearance of each actor is fixed. Besides formal rules, informal rules are still in effect. Since geo-disaster governance strongly concerns public well-being and persists over a long period of time, the majority of the system and all governors are public sectors. Additionally, governors prefer public-owned enterprises and geological teams because it is convenient to claim responsibility and to be influenced.

\subsubsection{Position Rules}

Position rules construct positions of actors in geo-disaster governance and then influence the structure of the governance. In this case, position rules in the whole process are mixed by functional rules and territorial rules, so the structure in each situation is different and is sometimes a mixture. As the aim of governance changes, the rules change from function-oriented to territory-oriented. In the pre-disaster situation, position rules constitute vertical governance linked up by specialized decision-making, the functional department is the governor or main executor, and the county government is just a symbolic role. In-disaster governance is a mixture of functional and territorial governance. The vertical functional regime would change into the horizontal territorial regime involving various actors led by the Headquarters, when potential risk in emergency duty turns into real losses in emergency response. Since territorial rules are mainstream in the post-disaster situation, county government controls the governance. The different position rules focusing on different aspects results in changes in actors' roles.

\subsubsection{Scope Rules}

Scope rules, including administrative ones and spatial ones, define the functional area of disaster governance. In terms of administrative scope, scope rules inside the governance in CQ TGRR are focusing on disaster itself, which is material. From the previous analysis, it is inferred that actions concentrate on disasters rather than the people who would be endangered. Pre-disaster governance aims to monitor and to prevent disasters and to nearly reduce risks of major ones. The governance in the last two situations focuses on materials rather than society, so the measurements mainly concern technology and engineering. The scope rules influence the change of governor. Since the causes of disaster are regional and the disaster area is local, the governor changes from CQ BPNR to the County Government. Moreover, given that in most cases, each local government concerns its own disaster area, the planning of post-disaster cannot be comprehensive and is not implemented as the whole, resulting in redundant constructions and resources waste.

In terms of spatial area, scope rules influence geo-disaster in CQ as a whole. CQ's geo-disaster governance can be divided into two parts, the reservoir area and the outside area. Due to the importance of CQ's TGRR, the whole society pays much more attention to geo-disaster governance in a reservoir 
area that occupies the majority of resources. The other area in CQ is more or less neglected, which leads to its proportion of potential geo-disaster spots rising from $69 \%$ in 2003 to $77 \%$ in 2015 [50].

\subsubsection{Choice Rules}

Choice rules define the methods that actors conduct in disaster governance. The basic logic of choice is identifying and eliminating substantial risks, which is in accordance with scope rules. Both mass monitoring and prevention and professional monitoring aim to find potential risks and to constantly guard against them through different methods. In order to directly eliminate risk, the engineering method is the only way governors can choose, and the technological method is the only approach governors would like to trust, not only in CQ, but also all over China, because technocracy is popular and dominates social ethos. Although in post-disaster, local government has multiple methods to govern, the choice rules always limit methods to engineering in reality. If the object of government changes from disaster to people, the risks themselves would not be directly controlled and the outcome would be more uncertain because societal factors are more flexible.

\subsubsection{Information Rules}

Information rules affect the acquisition of information about disaster. In this case, information rules render the governance technical and hierarchical. The demand for validity of information induces geo-disaster governance to connect with professionals and technology. No matter in which action situation, the expert system always plays a positive role in providing suggestions, including experts and engineers from functional departments. Although information in mass monitoring and prevention is produced by normal people, the training system and high-tech equipment ensure its validity. All information flows level-by-level, and public sectors are basically guided by the superiors, no matter if it is the bottom-up flow in pre-disaster and in-disaster, or the top-down flow in the post-disaster. Through the hierarchical transmission, some data would be delayed or even leaked slightly.

\subsubsection{Aggregation Rules}

Aggregation rules affect the strength of controlling disaster governance. This case has two connected features, strong control and capable actor. The strong control needs capable actors, and capable actors promote strong control. The capable actors are governors in three situations who can easily mobilize all actors and make all decisions due to the top-down system. Enterprises, residents, and other actors more like getting involved passively because they could not aggregate unless governors provide opportunities.

\subsubsection{Payoff Rules}

Payoff rules affect incentives and penalties in disaster governance. The main punishment of geo-disaster governance is the accountability system, which is a great deterrent to public sectors. Once a geo-disaster is ascertained as a human-made disaster, some civil servants would be punished and even be sent to jail. In 2001, the landslide that caused a death toll of 79 people resulted in nine civil servants gaining political demerits [51]. Incentives for public sectors are insufficient. Civil servants have a few promotion prospects and a few opportunities to move to other departments since geo-disaster is believed to be a specialized technological field. One interviewee said that if there is no accident, no one cares about geo-disasters; if there is an accident, everyone suffers.

In order to avoid any geo-disaster risk, governance wants to eliminate risk through engineering. In order to avoid any political risk, public sectors want to share the responsibility with other organizations. Even if an accident were to happen, the liability would be partly shared with the organization that undertakes engineering projects. 


\subsection{Evaluative Criteria}

Evaluative criteria include economic efficiency, fiscal equivalence, equity, accountability, adaptability, and moral values. They influence outcomes (Figure 2), and because of interactions, some evaluative criteria would be interpreted into other components. For example, accountability turns into payoff rules. Consequently, the following analyze four criteria. Because of the feature of certain systems, some criteria even disappear. For example, adaptability is not a criterion in the top-down system.

\subsubsection{Economic Efficiency}

Economic efficiency in this case limits the attendance of enterprise and moderately stimulates public participation. Because geo-disaster governance is a kind of public well-being, economic efficiency is not the priority. For enterprises, they earn a comparatively small profit from projects of public well-being and burdens a long-term and huge responsibility. For public sectors, they prioritize preventing losses and casualties rather than efficient economic use. Moreover, the projects of geo-disaster need specialized technology and certification. Therefore, private companies do not have enough incentive or even qualification to undertake them with low economic return. However, economic incentive stimulates residents to be involved. The monitors selected by normal people can get subsidies, which facilitates mass monitoring and prevention. The payment is low but still reasonable, considering that it is just a part-time job.

\subsubsection{Fiscal Equivalence}

Fiscal equivalence strengthens the role of engineering projects in geo-disaster governance. Because of the political and strategical importance, CQ's TGRR is the region where governors can receive colossal funds from the central government, resulting in governors always ignoring the economic costs. Meanwhile, actors should spend all the money the central government allocates, which suits engineering needing huge amounts of money. Consequently, the governor's indifference to the money resource strengthens the choice of engineering that needs money.

\subsubsection{Equity}

Equity emphasizes disadvantaged groups' access to resources. Governors believe strong control and public sectors can make governance a more equitable process to reduce misconduct, according to the interview. Thus, public sectors as governor control the whole resource, view most other actors as the passive receiver rather than the active participator, and are unwilling to introduce private enterprise into governance.

\subsubsection{Moral Values}

Moral values mean moral level of geo-disaster governance, which directly influences the quality of governance. Actors who have a higher moral level can be trusted more by the governor. Governors believe the moral level of the residents and enterprises is possibly lower than that of public sectors, so the main collective actions are taken by public sectors rather than the others. On the contrary, they believe the expert system has a high level of morality, causing it to actively participate in three situations. Additionally, in order to avoid ethical dilemmas, governors prefer technology and engineering, which do not possess moral values.

\section{Conclusions and Discussion}

In the last section, we conclude the previous analysis to answer and discuss the research questions: How does China perform daily geo-disaster governance on the local level? What are the possible causes? Then, we provide some policy implications for geo-disaster governance as it has gained significant traction among both academics and policymakers [52]. 


\subsection{The Features of China's Geo-Disaster Governance}

The daily geo-disaster governance is a centralized hierarchical system as a whole. The governor has decisive power, and most actors are passively taken by the framework. Whether they would enter and what positions they hold are not decided by themselves but by the governor, as we analyzed. This shows how directly and actively they get involved and, at the same time, indicates how highly local governments think of geo-disaster governance. In terms of actors' attributes, it has already formed a multi-agent network, but the public sector still has great power; in terms of decision-making, governors make decisions and design procedures that are conducted by executors. Within the top-down structure, mass monitoring, and prevention, the bottom-up action still plays an important role; hence it covers all spots of potential geo-disaster. On the one hand, mass monitoring and prevention mobilizes local people, and its routine is totally done by them; on the other hand, it is still started and guided by BPNR. It is better to say that governors tactically organize the bottom-up action into the centralized hierarchical framework. The centralized system indeed is against local communities, but it is difficult for a local community to build local capacity without external supports in a developing context. It is the principal weakness of community-based disaster governance as well [53]. Local governments need to empower local communities, and daily disaster governance plays an active role [54], especially in developing countries [55]. Their relationship is complementary rather than alternative. Meanwhile, any endeavor towards community resilience should be encouraged [56], so we believe that this case sets an example for related research and practice of local disaster governance.

The whole daily geo-disaster governance is a typical matrix of fragmentation resulting in a disconnection among action situations. The Chinese administrative system can be divided into two types. The first one is the vertical and functional system called Tiao in Chinese, and the second one is horizontal and territorial system, called Kuai in Chinese. Capable actors, as the pivot in the governance, break the traditional boundary between systems and connects them. Some of them integrate this fragmentation. CQ BPNR is supervised by CQ municipal government and is guided by the Ministry of Land and Resources. Each action situation has a clear responsibility division, but from the view of a comprehensive disaster cycle, the main responsibility is gradually transferred from a functional system to a territorial system, which leads to gaps among the three situations. The geo-disaster governance is not consistent because each action situation has its own governor and framework, which differ from each other. In pre-disaster governance, CQ BPNR is the governor in the functional framework; in in-disaster governance, CQ BPNR and the Headquarters are the governor in the framework mixing functional governance and territorial governance; in post-disaster situation, local government decides everything. The changes among three situations separate the geo-disaster governance as an integrity, which produces information and resources waste. For example, professional suggestions for pre-disaster from CQ BPNR and advice for in-disaster from CQ BEM cannot be completely delivered to each county; when the county builds a new town or revamps a damaged area, the idea or target would not be oriented towards disaster governance, making it difficult to enhance community resilience. This problem appears in other cases in China as well, and some researchers argue that the matrix of fragmentation hinders the collective action [57,58]. We, however, insist that the collective action in each situation be smooth, while the problem is the changes in action situations. Furthermore, due to recent institutional reform, both CQ BPNR and CQ BEM have function and responsibility in the situation of in-disaster, which results in ambiguity needing more studies in the future.

According to the method of governance, the geo-disaster governance relies on technology, engineering, and profession. In pre-disaster governance, professional monitoring uses advanced technology to pursue precise information of geo-disaster, and mass monitoring and prevention need some professional equipment as well. Pre-disaster governance desires the use of engineering projects to eliminate potential risks by changing natural conditions. Reconstruction in post-disaster governance relies on constructions as well as emphasizing buildings, which accords with the phenomenon that the governor always ignores the anti-disaster capacity or resilience in post-disaster [50]. In-disaster and 
post-disaster need professional advice from expert systems. The majority of the data supporting decision-making are not pure or first-hand data, but the data produced by technological equipment. Mass monitoring and prevention, playing an increasingly important role, just serves engineering projects, and its process cannot leave technology.

\subsection{The Determinants of the Geo-Disaster Governance}

In conclusion, widespread geo-disasters, dominated formal rules, the attempt to control all risks, abundant public funding, and worries about equity and morality altogether empower authority and legitimacy of the governor and limit the participation of other actors, which leads to the centralized system and intensifies the public sector. Disaster governance is always a major issue within local governments in China. Both of them, albeit with different governmental consideration, are rooted in their respective traditions. The promotion of individualism and privatization-the stable and longtime tradition of America-generates powerless local governments that are unable to mobilize resources so as to strengthen bottom-up activities $[59,60]$. However, the tradition of China, a centralized government, is totally opposite, empowering public sectors at the local level. The idea that government ought to take responsibility for well-being appears as a top-down system controlled by formal institutions. Mass monitoring and prevention is indeed public engagement, but it should be promoted more and diversified.

The mixture of functional governance and territorial governance renders governance discontinued during situation changes and shapes CQ BPNR as the pivot. Disasters happen in certain territories and their governance is certainly professional, so both territorial and functional organization have the right and opportunity to it. This kind of institutional arrangement does not only show in geo-disaster governance but also shows in economics [61], environment [58] etc., as the institutional background. Although the matrix of fragmentation generally decreases efficiency and even causes malfunction in China's governance [62], this case shows that a capable actor connecting the vertical system and horizontal system partly overcomes troubles. Troubles appear as poor communication and overlapping management. This case, in the bigger picture, gives China's public administration a hint about empowering the connector. The connector can communicate with both sides and integrate the responsibility and power of both sides to reduce the overlap. Yet still there is separation among three situations, which needs amendment further.

The preference for technology, engineering, and profession is mainly shaped by attributes of community, scope rules, choice rules, payoff rules, and fiscal equivalence. In conclusion, potential distrust of knowledge of local people, insisting geo-disaster risk itself, basic logic of decision-making, and soft budget limitation all contribute to the preference. The social ethos of technocracy also promotes it. It is not rare that disaster studies emphasize the importance of profession [63,64], and technology [65,66], especially in pre-disaster situation. The preference is shaped by institutional arrangement rather than technological consideration. Using the technical approach in pre-disaster situation can ensure safety normally, and public sectors can protect themselves from liability concerns when disasters happen, since they could shift the responsibility to technology and engineering. The preference leaves a problem in which technology, engineering, and profession cannot coordinate with local people well. For example, early warning systems informed local people by audible alarms, broadcast, and mobile phone during the Changning Earthquake on June 17, 2019, and took the desired effect [67]. However, many people were still unfamiliar with this system and did not know how to respond, thereby weakening its effectiveness.

\subsection{Policy Implication}

According to the previous analysis, we would like to give some policy suggestions for disaster governance due to the value in the practical dimension [52]. 


\subsubsection{From Disaster-Oriented to People-Oriented}

Disaster governance should transform from being disaster-oriented to people-oriented. The current disaster governance aims to find and then remove all geological risks, and its orientation is disaster rather than people who would suffer disaster. However, biophysical conditions determine that the disaster risk in CQ's TGRR cannot be completely eliminated and financial resources cannot support either. All actors have to accept and respect the fact that they have to coexist with disasters. From the perspective of sociology of disaster, only in the society can landslides, debris flow be called geo-disasters, or just can be viewed as geographical phenomena.

Public education would be the key approach to build a people-oriented system. The previous studies show the effectiveness of disaster education across the world [68,69]; the case studies in China, however, show the low education level of disaster mitigation and governance [70,71]. Our analysis shows the value of public education as well since both professional monitoring and mass monitoring and prevention include the training. In order to promote local resilience, we suggest that local governments launch more public education programs about geo-disasters, and encourage more disaster-related training in professional education as well.

\subsubsection{From Discontinuity to Continuity}

Disaster governance needs an integrated framework rather than several different frameworks in three situations. The changes among them increase the communication costs because the ensuing actors cannot smoothly inherit the previous construction, knowledge, and information. Consequently, policy-makers should redesign a united framework, which concludes three situations, and even enacts the basic law for disaster. For example, Japan enacted Disaster Countermeasures Basic Act in 1961, which was revised more than 50 times [72].

Although the same governance patter might not suit all regions of China, we believe that, in this area, the disaster governance should be a dual-governors system to fill the gaps among situations. For instance, CQ BPNR and the County government are co-governors. CQ BPNR mainly aims for the natural aspect of geo-disasters and the specialized knowledge and technology, while local governments mainly aim for the social aspect of geo-disasters and resource mobilization.

\subsubsection{From Singular to Diverse}

The relatively singular structure should be changed to a diverse structure, in terms of method and actor. The priority of engineering isolates ordinary people from geo-disaster governance because it needs professional knowledge and a large amount of money. We suggest increasing resilience and reducing vulnerability in this area, so social measures can benefit geo-disaster governance as well. For example, organizing victims to learn techniques of handcrafts and vocational skills, adjusting the economic structure of the disaster-affected area, and increasing the cohesion in community could be effective. In addition, these measures can be taken by enterprise or NGOs rather than the public sector, inviting more actors into the geo-disaster governance.

This paper introduces the IAD framework to the case study of geo-disaster governance in CQ's Three Gorges at the local level. Based on it, future study can focus on the three issues. The first one is conducting quantitative studies within the IAD framework; the second one is more empirical studies within the IAD framework; and the third one is discussing the role of technology, such as GIS, information visualization, and engineering in disaster governance due to their important role, and how they can cooperate with people.

Author Contributions: Conceptualization, A.R. and C.Z.; methodology, A.R.; data and analytical materials, L.Z.; writing - original draft preparation, A.R.; writing — review and editing, A.R. and J.F.; supervision and funding acquisition, C.Z. All authors have read and agreed to the published version of the manuscript.

Funding: This research was funded by Major research projects of NSSFC, grant number 18VDL015. 
Acknowledgments: The authors wish to thank Shihong Zhou for his support of this study and Peng He for his participation.

Conflicts of Interest: The authors declare no conflict of interest.

\section{References}

1. Swiss Re Institute. Catastrophes-Total Losses. Available online: http://www.sigma-explorer.com (accessed on 28 June 2017).

2. International Federation of Red cross and Red Crescent Societies. World Disasters Report 2016 Resilience: Saving Lives Today, Investing for Tomorrow; Imprimerie Chirat: Lyon, France, 2016.

3. National Bureau of Statistics of PRC, Statistical Communique of the People's Republic of China on the 2018 National Economic and Social Development. Available online: http://www.stats.gov.cn/english/PressRelease/ 201902/t20190228_1651335.html (accessed on 28 May 2019).

4. Johnson, L.A.; Olshansky, R.B. After Great Disasters: How Six Countries Managed Community Recovery; Lincoln Institute of Land Policy: Cambridge, MA, USA, 2016.

5. Beck, U. Risk Society: Towards a New Modernity; Sage: London, UK, 1992.

6. Ahrens, J.; Rudolph, P.M. The importance of governance in risk reduction and disaster management. J. Conting Crisis Man. 2006, 4, 207-220. [CrossRef]

7. Tierney, K.J. From the margins to the mainstream? Disaster research at the crossroads. Annu. Rev. Sociol. 2007, 33, 503-525. [CrossRef]

8. Prater, C.S.; Lindell, M.K. Politics of hazard mitigation. Nat. Hazards Rev. 2000, 1, 73-82. [CrossRef]

9. Lim, W.K. Understanding risk governance: Introducing sociological neoinstitutionalism and foucauldian governmentality for further theorizing. Int. J. Disast. Risk Sc. 2011, 2, 11-20. [CrossRef]

10. Fortun, K.; Knowles, S.G.; Choi, V.; Jobin, P.; Matsumoto, M.; De la Torre III, P.; Liboiron, M.; Murillo, L.F.R. Researching Disaster from an STS perspective. In The Handbook of Science and Technology Studies; Felt, U., Fouche, R., Miller, C.A., Smith-Doerr, L., Eds.; MIT Press: Cambridge, MA, USA, 2017; pp. 1003-1028.

11. Shi, P. On the role of government in integrated disaster risk governance-Based on practices in China. Int. J. Disast. Risk Sc. 2012, 3, 139-146. [CrossRef]

12. Lu, Y.; Xu, J. NGO collaboration in community post-disaster reconstruction: Field research following the 2008 Wenchuan earthquake in China. Disasters 2015, 39, 258-278. [CrossRef]

13. Zhang, X.; Yi, L.; Zhao, D. Community-based disaster management: A review of progress in China. Nat. Hazards 2013, 65, 2215-2239. [CrossRef]

14. Teets, J.C. Post-earthquake relief and reconstruction efforts: The emergence of civil society in China? China $Q$. 2009, 198, 330-347. [CrossRef]

15. Guo, X.; Kapucu, N. Network performance assessment for collaborative disaster response. Disaster Prev. Manag. 2015, 24, 201-220. [CrossRef]

16. Zhang, L.; Li, L. People-oriented emergency response mechanism-An example of the emergency work when typhoon Meranti stroked Xiamen. Int. J. Disast. Risk Re. 2019, 38, 101185. [CrossRef]

17. Ye, T.; Shi, P.; Liu, L.; Fan, Y.; Hu, J. China's drought disaster risk management: Perspective of severe droughts in 2009-2010. Int. J. Disast. Risk Sc. 2012, 3, 84-97. [CrossRef]

18. Yi, L.; Ge, L.; Dong, Z.; Zhou, J.; Gao, Z. An analysis on disasters management system in China. Nat. Hazards 2012, 60, 295-309.

19. Chang, Y.; Wilkinson, S.; Brunsdon, D.; Seville, E.; Potangaroa, R. An integrated approach: Managing resources for post-disaster reconstruction. Disasters 2011, 35, 739-765. [CrossRef] [PubMed]

20. Kapucu, N. Collaborative governance in international disasters: Nargis cyclone in Myanmar and Sichuan earthquake in China cases. J. Emerg. Manag. 2011, 8, 1-25. [CrossRef]

21. Ostrom, E. Understanding Institutional Diversity; Princeton University Press: Princeton, NJ, USA, 2005.

22. World Bank. World Development Report 2014: Risk and Opportunity-Managing Risk for Development; World Bank: Washington, DC, USA, 2014.

23. Renn, O. Risk Governance: Coping with Uncertainty in A Complex World; Earthscan: London, UK, 2008.

24. Zinn, J.; Taylor-Gooby, P. (Eds.) Risk as an Interdisciplinary Research Area. In Risk in Social Science; Oxford University Press: Oxford, UK, 2006; pp. 20-53. 
25. Tierney, K.J. Disaster governance: Social, political, and economic dimension. Annu. Rev. Env. Resour. 2012, 37, 341-363. [CrossRef]

26. Ostrom Workshop IAD FRAMEWORK Institutional Analysis \& Development-IAD Framework. Available online: https://ostromworkshop.indiana.edu/resources/library/subject-bibliographies/IADframework.html (accessed on 30 March 2019).

27. Ostrom, E. Vulnerability and polycentric governance systems. IHDP Update 2001, 3, 1-4.

28. Fleischman, F.D.; Boenning, K.; Garcia-Lopez, G.A.; Mincey, S.; Schmitt-Harsh, M.; Daedlow, K.; Lopez, M.C.; Basurto, X.; Fischer, B.; Ostrom, E. Disturbance, response, and persistence in self-organized forested communities: Analysis of robustness and resilience in five communities in southern Indiana. Ecol. Soc. 2010, 15, 9. [CrossRef]

29. McGinnis, M.D. An introduction to IAD and the language of the Ostrom workshop: A simple guide to a complex framework. Policy Stud. J. 2011, 39, 169-183. [CrossRef]

30. Comfort, L.K. Social Network Interaction among Nested Sets in Dynamic Contexts: Disaster Operations as a Laboratory for Social Change; Spatio-Temporal Constraints on Social Networks Workshop; Center for Spatial Studies, University of California: Santa Barbara, CA, USA, 2010.

31. Abel, T.D.; Stephan, M.; Daley, D. Climate Risk Polycentricity and the IAD Framework; Workshop on the Ostrom Workshop 5; Indiana University: Bloomington, IN, USA, 2014. Available online: http://citeseerx.ist.psu.edu/ viewdoc/download?doi=10.1.1.881.5990\&rep=rep1\&type=pdf (accessed on 5 September 2017).

32. Cuevas, S.C.; Peterson, A.; Morrison, T.; Robinson, C. Methodology for examining the challenges in mainstreaming climate change adaptation. Int. J. Clim. Chang. Str. 2016, 8, 418-439. [CrossRef]

33. Maja, B. Institutional Dimension of Flood Risk: Understanding Institutional Complexity in Flood Risk Management for the Case of St Maarten. Master Thesis, Delft University of Technology, Delft, The Netherlands, 15 January 2017. Available online: https://repository.tudelft.nl/islandora/object/uuid:3f68966d-7780-47ba8d89-87d8de1b1dc9/datastream/OBJ/download (accessed on 23 December 2017).

34. Ostrom, E. A Framework for Institutional Analysis; DFM Workshop on Democracy and Governance, Associates in Rural Development: Bloomington, IN, USA, 1991; pp. 13-31.

35. Ostrom, E. Background on the institutional analysis and development framework. Policy Stud. J. 2011, 39, 7-27. [CrossRef]

36. Ostrom, E.; Gardner, R.; Walker, J. Rules, Games, and Common-Pool Resources; The University of Michigan Press: Ann Arbor, MI, USA, 1994.

37. Xinhua News Agency. Implement the idea of development, including innovation, coordination, green, openness and share. Ensure completion of overall well-off society goals in time. People's Daily 7 January 2016.

38. Chongqing Geo-Disaster Prevention and Control Center. Basic Information of Geological Environment in Chongqing's Three Gorges Reservoir Region; Chongqing Geo-Disaster Prevention and Control Center: Chongqing, China, 2015. (In Chinese)

39. Gao, Q.; Xu, M.; Li, B.; Xu, W.; Wang, H. Distribution Characteristics of Area Rainfall in the Three Gorges Reservoir for Recent 40 Years. Adv. Meteorol. Sci. Technol. 2018, 8, 76-81. (In Chinese)

40. Zhao, P.; Yang, P.; Jiang, L.; Du, C. Situation of Geologic Hazards Induced by Heavy Rainfall in Northeast Chongqing. J. Yangtze River Sci. Res. Inst. 2017, 34, 50-56. (In Chinese)

41. Piao, S.; Ciais, P.; Huang, Y.; Shen, Z.; Peng, S.; Li, J.; Zhou, L.; Liu, H.; Ma, Y.; Ding, Y.; et al. The impacts of climate change on water resources and agriculture in China. Nature 2010, 467, 43. [CrossRef]

42. Chongqing Statistics Bureau; National Bureau of Statics Survey Office in Chongqing. Chongqing Statistical Yearbook 2015; China Statistics Press: Beijing, China, 2016. (In Chinese)

43. Yin, Y.; Wang, H.; Gao, Y.; Li, X. Real-time monitoring and early warning of landslides at relocated Wushan Town, the Three Gorges Reservoir, China. Landslides 2010, 7, 339-349. [CrossRef]

44. China Three Gorges Corporation. China Three Gorges Construction Yearbook 2013; Media Co., Ltd. China Three Gorges Corporation: Yichang, China, 2013. (In Chinese)

45. Liu, J.F.; Huang, D.D. The generation and explanation of culture of immigration in Three Gorges. Study Pract. 2011, 7, 135-140. (In Chinese)

46. Chen, S.Y.; Zou, B.H.; Wang, S.D. Culture and economic development in Chongqing. J. Chongqing Univ. (Soc. Sci. Ed.) 2004, 10, 27-29. (In Chinese)

47. Zhou, L.; (Chongqing Municipal Bureau of Land and Resources, Chongqing, China); Guo, H.; (Chongqing Municipal Bureau of Land and Resources, Chongqing, China). Personal communication, 2016. 
48. Tao, P.; Chen, C. Towards a politics of disaster response: Presidential disaster instructions in China, 1998-2012. Disasters 2018, 42, 275-293. [CrossRef]

49. Li, S. On Historical Review and Development Strategy: Mass Observation and Mass Preparedness of Earthquake Disasters. J. Inst. Disaster Prev. 2009, 11, 96-101. (In Chinese)

50. Chongqing Geo-Disaster Prevention and Control Center. The Annual Summary Sheet of Potential Geo-Disaster Spots (2015); Chongqing Geo-Disaster Prevention and Control Center: Chongqing, China, 2015. (In Chinese)

51. The State Council. The Circular of the State Council on the Investigation and Treatment of Human Responsibility for Geological Disaster Accidents in Wulong, Chongqing; The State Council: Beijing, China, 2001.

52. Arun, A. A positive side of disaster. Nature 2011, 473, 291-292.

53. Allen, K.M. Community-based disaster preparedness and climate adaptation: Local capacity-building in the Philippines. Disasters 2006, 30, 81-101. [CrossRef]

54. Col, J.M. Managing disasters: The role of local government. Public Adm. Rev 2007, 67, 114-124. [CrossRef]

55. Kusumasari, B.; Alam, Q. Bridging the gaps: The role of local government capability and the management of a natural disaster in Bantul, Indonesia. Nat. Hazards 2012, 60, 761-779. [CrossRef]

56. Bowles, R.; Anderson, G.S.; Vaughan, C. Building resilient communities: A facilitated discussion. J. Emerg. Manag. 2016, 14, 233-243. [CrossRef]

57. Zhang, Q.; Hu, Y.; Lu, Q. Is It Possible to Integrate Disaster Governance into Urbanization? Evidence from Chinese Townships Hit by 2008 Wenchuan Earthquake and 2013 Lushan Earthquake. In Disaster Governance in Urbanising Asia; Miller, M.A., Douglass, M., Eds.; Springer: Singapore, 2016; pp. 211-236.

58. Zhan, X.; Tang, S.Y. Political opportunities, resource constraints and policy advocacy of environmental NGOs in China. Public Adm. 2013, 91, 381-399. [CrossRef]

59. Wolensky, R.P.; Wolensky, K.C. Local Government's Problem with Disaster Management: A Literature Review and Structural Analysis. Rev. Policy Res. 1990, 9, 703-725. [CrossRef]

60. Ha, K.M.; Ahn, J.Y. Local Emergency Management Systems in the United States and Korea. J. Emerg. Manag. 2010, 8, 61-71.

61. Guo, S. Designing market socialism: Trustees of state property. Critique 2005, 33, 218-247. [CrossRef]

62. Mertha, A.C. China's "Soft" Centralization: Shifting Tiao/Kuai Authority Relations. China Q. 2005, 184, 791-810. [CrossRef]

63. Somers, S.; Svara, J.H. Assessing and managing environmental risk: Connecting local government management with emergency management. Public Adm. Rev. 2009, 69, 181-193. [CrossRef]

64. Kemp, R.L. Comments on "assessing and managing environmental risk: Connecting local government management with emergency management". Public Adm. Rev. 2009, 69, 197-199. [CrossRef]

65. Collins, M.L.; Kapucu, N. Early warning systems and disaster preparedness and response in local government. Disaster Prev. Manag. 2008, 17, 587-600. [CrossRef]

66. Nguh, J. Have Maryland local health departments effectively put in place the information technology relevant to emergency preparedness? J. Emerg. Manag. 2013, 11, 73-91. [CrossRef] [PubMed]

67. Wang, Q. Modern communication system: Conception, structure and boundary-Based on the communication analysis of the Changning 6.17 Earthquake. J. News Res. 2019, 10, 46-48. (In Chinese)

68. Takahashi, K.; Inomo, H.; Shiraki, W.; Isouchi, C.; Takahashi, M. Experience-Based Training in Earthquake Evacuation for School Teachers. J. Disaster Res. 2017, 12, 782-791. [CrossRef]

69. De Mendonca, M.B.; Valois, A.S. Disaster education for landslide risk reduction: An experience in a public school in Rio de Janeiro State, Brazil. Nat. Hazards 2017, 89, 351-365. [CrossRef]

70. Huang, B.; Li, J.; Li, Y.; Zhang, W.; Pan, F.; Miao, S. Need for continual education about disaster medicine for health professionals in China-a pilot study. BMC Public Health 2011, 11, 89. [CrossRef] [PubMed]

71. Wei, B.; Su, G.; Liu, F. Public response to earthquake disaster: A case study in Yushu Tibetan Autonomous Prefecture. Nat. Hazards 2013, 69, 441-458. [CrossRef]

72. Cabinet Office Government of Japan. Disaster Countermeasures Basic Act. (In Japanese). Available online: http://www.houko.com/00/01/S36/223.HTM (accessed on 29 June 2017).

(C) 2020 by the authors. Licensee MDPI, Basel, Switzerland. This article is an open access article distributed under the terms and conditions of the Creative Commons Attribution (CC BY) license (http://creativecommons.org/licenses/by/4.0/). 